Original Article

\title{
Utilizing Geographic Information System in Evaluation of Spatial Distribution and Epidemiology of Cryptosporidium Species in Diarrheic Humans in Mazandaran Province, North of Iran
}

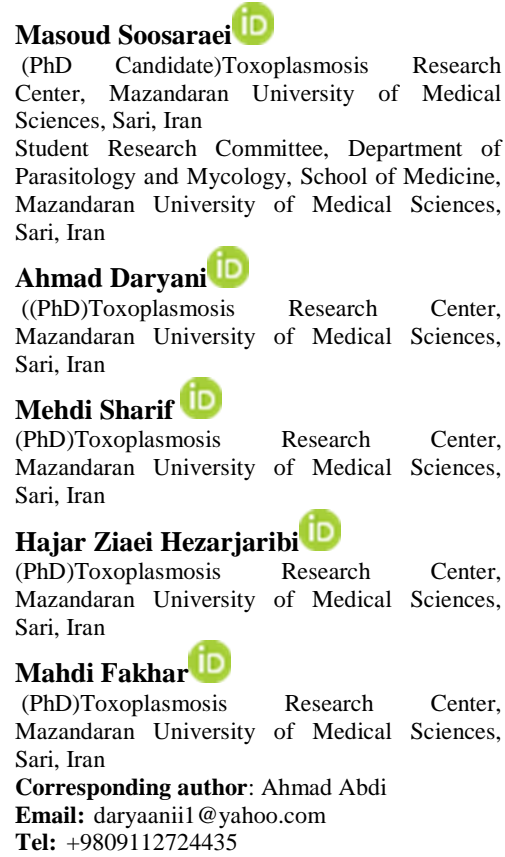

Hajar Ziaei Hezarjaribi

$(\mathrm{PhD})$ Toxoplasmosis Research Center, Mazandaran University of Medical Sciences, Sari, Iran

Mahdi Fakhar iD

$(\mathrm{PhD})$ Toxoplasmosis Research Center, Mazandaran University of Medical Sciences, Sari, Iran

Corresponding author: Ahmad Abdi

Email: daryaanii1@yahoo.com

Tel: +9809112724435

Address: Mazandaran University of Medical Sciences, Sari, Iran

Received: $2020 / 06 / 1$

Revised: 2020/12/19

Accepted: 2020/12/19

\section{cc) (i) \&}

This work is licensed under a Creative Commons Attribution 4.0 License.

\begin{abstract}
Background and objectives: Cryptosporidium spp. is a major cause of gastrointestinal illness in humans. There are no data available on geospatial distribution of Cryptosporidium spp. in the Mazandaran Province, Iran. Therefore, the aim of this study was to determine the spatial patterns and demographic factors associated with Cryptosporidium spp. infection in the Mazandaran Province, North of Iran.
\end{abstract}

Methods: Fecal specimens were collected from diarrheic individuals $(n=215)$ who were referred to health centers in the Mazandaran Province during 2014-2015. The specimens were examined for presence of Cryptosporidium spp. oocysts by Ziehl-Neelsen acid-fast staining.

Results: Cities of Sari, Neka, Noshahr and Behshahr were identified as disease hotspots. The prevalence of Cryptosporidium infection was significantly higher in subjects under 10 years of age as well as those living in low-altitude areas and rural areas without access to standard water sources.

Conclusion: Our findings and the GIS-derived data could be used to facilitate cryptosporidiosis surveillance and monitoring of Cryptosporidium spp. distribution in the study area.

Keywords: Cryptosporidium spp., prevalence, diarrhea, Mazandaran, Iran. 


\section{INTRODUCTION}

Cryptosporidium spp. is a protozoan from the genus Cryptosporidium and a major cause of gastrointestinal illness in humans (1). The parasite is a well-known opportunistic pathogen of immunocompetent individuals. Cryptosporidium spp. invades epithelial cells of the intestinal and respiratory tracts of vertebrates $(2,3)$. Cryptosporidiosis is typically characterized by watery, profuse, non-bloody diarrhea. Other symptoms can include anorexia, fever, vomiting, fatigue, headache, weight loss, cramps and abdominal pain (4). Asymptomatic infection can also occur (5-8). Recurrence of symptoms after apparent resolution has been frequently reported; however, cryptosporidiosis is often self-limiting, and symptoms completely resolve within 2-3 weeks in immunocompetent people (9). There are a variety of methods for the detection of Cryptosporidium oocysts, including immunological and molecular techniques and microscopy. Microscopic methods involves staining of fecal smears for identification of Cryptosporidium oocysts, which is usually difficult (10). The modified acidfast staining is an effective technique that characterize oocytes as as pink to red, ovoid to spherical, bodies on a blue or purple background (11).

Medical parasitology informatics focuses on the use of information science and technology in research. Geographical information system (GIS) modifiable areal unit problem (MAUP) is a common tool used in this field because it can illustrates relationships between diseases, locations and disease clusters. This technology allows evaluation of digital map data generated by earth satellite sensors for spatial and temporal environmental analyses. This facilitates prediction of cryptosporidiasis transmission, spatial distribution and epidemiological aspects and in turn provides beneficial information for decision-making and policy planning. The application of GIS is very valuable in medical parasitology for study design, territorial sampling and drawing disease maps (12).

The aim of this study was to determine the epidemiological aspects and spatial distribution of Cryptosporidium spp. Infection in patients with diarrhea in the
Mazandaran Province, North of Iran, using GIS.

\section{MATERIALS AND METHODS}

This cross-sectional research was performed on 4,000 individuals referring to health centers of Mazandaran Province from July 2014 to June 30, 2015. Fecal samples were collected in sterile plastic bottles from subjects with diarrhea $(\mathrm{n}=215)$. The subjects were grouped according to age. Fecal smears were prepared by formalin-ether sedimentation, and examined by modified acid-fast staining and microscopic evaluation (13). The intensity of infection was estimated semi-quantitatively according to the average number of oocysts in 20 randomly selected fields under $1,000 \times$ magnifications. The results were categorized as follows: negative (absence of oocyst), slight (1-5 oocysts), moderate (6-10 oocysts) and severe (> 10 oocysts) (11).

After obtaining written consent, sampling was done and demographic data were collected using a questionnaire. The specimens were preserved in polyvinyl alcohol and were transferred to the Parasitology Laboratory of Mazandaran University of Medical Sciences.

The location (latitude, longitude) where Cryptosporidium infection has been detected was recorded. The pattern of disease distribution was evaluated by spatial analysis and using MAUP. High/low clustering was applied to determine the distribution of Cryptosporidium.

Data were analyzed using SPSS 16.0 (SPSS Inc., Chicago, IL, USA) at significance of 0.05 . Local indicators of spatial association were used to characterize the distribution of Cryptosporidium and potential risk factors in various areas of the province. Additionally, geographically weighted regression (GWR) was applied to examine the geographical relationships between the occurrence of Cryptosporidium and related variables, including temperature and precipitation.

\section{RESULTS}

Overall, 17 (7.9\%) specimens were positive for Cryptosporidium oocyst. Cryptosporidium spp. oocysts appeared as pink to red, spherical to ovoid bodies in the modified acid-fast staining. The prevalence of Cryptosporidium oocyst was highest in subjects aged less than $10(2.79 \%)$ and lowest in subject over 51 years old $(0.46 \%)$ (Table 1$)$. There was a significant 
association between Cryptosporidium spp. infection and incidence of diarrhea $(\mathrm{P}<0.05)$. Moreover, the prevalence of Cryptosporidium spp. infection was significantly higher in children under 10 years old than other age groups $(\mathrm{P}<0.05)$. The results showed a significant association between the prevalence of Cryptosporidium and residence, occupation, age, anti-parasitic drug consumption and contact with domestic animals (Table 1).
The prevalence of Cryptosporidium was significantly higher in altitude of 500-1000 m from sea level $(\mathrm{P}<0.05)$. Mapping the infection rate of Cryptosporidium in the Mazandaran Province demonstrated that Sari $(8.1 \%)$ and Ramsar (1.3\%) districts had the highest and lowest prevalence of Cryptosporidium spp., respectively. The results also showed parts of the city of Sari, Neka, Joibar, Noshahr, Behshsar and nearby villages as potential disease hotspots.

Table 1. Potential demographic and geographic risk factors of Cryptosporidium spp. in subjects with diarrhea in the Mazandaran Province,

\begin{tabular}{|c|c|c|c|c|}
\hline Variable & No. samples & No. Positive (\%) & OR $(95 \% \mathrm{CI})$ & P-value \\
\hline \multicolumn{5}{|l|}{ Age (years) } \\
\hline$<10$ & 56 & $8(14.2)$ & 1.0 & \\
\hline $11-20$ & 64 & $2(3.1)$ & $5.1(1.1-36.5)$ & 0.04 \\
\hline 21-30 & 40 & $2(5)$ & $0.3(0.03-1.7)$ & 0.1 \\
\hline $31-50$ & 62 & $3(4.8)$ & $0.3(0.04-1.3)$ & 0.1 \\
\hline$>51$ & 28 & $2(7.1)$ & $0.4(0.04-2.5)$ & 0.4 \\
\hline \multicolumn{5}{|l|}{ Sex } \\
\hline Male & 135 & $10(7.4)$ & $1.2(0.4-3.9)$ & 0.8 \\
\hline Female & 115 & $7(6.1)$ & 1.0 & \\
\hline \multicolumn{5}{|l|}{ Residence } \\
\hline Rural & 119 & $13(10.9)$ & $3.8(1.1-16.7)$ & 0.02 \\
\hline Urban & 131 & $4(3.1)$ & 1.0 & \\
\hline \multicolumn{5}{|l|}{ Water source } \\
\hline Standard & 165 & $5(3.1)$ & 1.0 & \\
\hline Non-standard & 85 & $12(14.1)$ & $0.1(0.05-0.6)$ & 0.002 \\
\hline \multicolumn{5}{|l|}{ Occupation } \\
\hline Student & 53 & $2(3.7)$ & 1.0 & \\
\hline Private business & 45 & $2(4.4)$ & $0.8(0.05-12.1)$ & 0.9 \\
\hline Housewife & 58 & $4(6.8)$ & $1.8(0.2-21.6)$ & 0.6 \\
\hline Government employee & 54 & $2(3.7)$ & $0.9(0.06-14.1)$ & 0.9 \\
\hline Farmer & 40 & $7(17.5)$ & $5.4(1.1-39.2)$ & 0.03 \\
\hline \multicolumn{5}{|l|}{ Educational level } \\
\hline Low & 179 & $147.8)$ & 1.0 & \\
\hline High & 71 & $3(4.2)$ & $1.9(0.5-10.7)$ & 0.4 \\
\hline \multicolumn{5}{|c|}{ Contact with domestic animals } \\
\hline Yes & 160 & $15(9.3)$ & $4.5(1.1-41.7)$ & 0.03 \\
\hline No & 90 & $2(2.2)$ & 1.0 & \\
\hline \multicolumn{5}{|l|}{ Season of disease onset } \\
\hline Winter & 67 & $2(2.9)$ & 1.0 & \\
\hline Spring & 62 & $4(6.4)$ & $0.4(0.03-3.2)$ & 0.3 \\
\hline Summer & 73 & $10(13.6)$ & $5.1(1.1-49.7)$ & 0.03 \\
\hline Autumn & 48 & $2(4.1)$ & $1.4(0.09-20.1)$ & 0.7 \\
\hline \multicolumn{5}{|c|}{ Anti parasitic drug consumption } \\
\hline Yes & 79 & $3(3.8)$ & 1.0 & \\
\hline No & 171 & $12(7.08)$ & $0.05(0.38-0.75)$ & 0.001 \\
\hline \multicolumn{5}{|l|}{ Temperature $\left(\mathbf{C}^{\circ}\right)$} \\
\hline$\leq 18$ & 94 & $2(2.1)$ & 1.0 & \\
\hline$>18$ & 156 & $15(9.6)$ & $0.2(0.02-0.9)$ & 0.03 \\
\hline \multicolumn{5}{|l|}{ Rainfall (mm) } \\
\hline$\leq 60$ & 119 & $4(3.3)$ & 1.0 & \\
\hline$>60$ & 131 & $13(9.9)$ & $0.3(0.07-1.1)$ & 0.04 \\
\hline \multicolumn{5}{|l|}{ Humidity (\%) } \\
\hline$\leq 70$ & 165 & $12(7.2)$ & 1.0 & \\
\hline$>70$ & 85 & $5(5.8)$ & $1.2(0.3-4.7)$ & 0.7 \\
\hline \multicolumn{5}{|l|}{ Height from the sea (m) } \\
\hline$<500$ & 84 & $3(3.5)$ & 1.0 & \\
\hline $500-1000$ & 96 & $12(12.5)$ & $0.2(0.05-0.9)$ & 0.03 \\
\hline & 70 & $2(2.8)$ & $0.8(0.09-7.1)$ & 0.8 \\
\hline \multicolumn{5}{|l|}{ Distance from the sea $(\mathrm{m})$} \\
\hline$<10000$ & 51 & $2(3.9)$ & 1.0 & \\
\hline 10000- 20000 & 142 & $10(7.1)$ & $0.5(0.05-2.6)$ & 0.7 \\
\hline$>20000$ & 57 & $3(5.2)$ & $1.6(0.1-20.2)$ & 0.6 \\
\hline
\end{tabular}




\section{DISCUSSION}

One of the most important advantages of GIS is the ability to integrate totally different databases into a single environment (14). This tool also allows linking of shared humananimal diseases data, which is beneficial for development of control and prevention programs (15). Rinaldi et al. used GIS for analysis and presentation of findings related to prevalence of canine parasites as potential zoonotic agents (14). This method allows mapping of cryptosporidiosis, development of descriptive disease maps, evaluation of relevant environmental variables such as topography, vegetation, land cover/ land use statistics, surveillance and monitoring of animal diseases, and prediction of disease incidence.

Our investigation showed that infection with Cryptosporidium was significantly more prevalent among individuals without history of anti-parasitic drug consumption.

The prevalence rate of cryptosporidiosis was significantly higher among farmers compared to subjects with other occupations, which could be due to the frequent exposure of farmers to soil and human waste.

In this study, the prevalence of Cryptosporidium spp. was $7.9 \%$. In general, the prevalence of Cryptosporidium spp. varies widely between different populations. For instance, the rate of cryptosporidiosis was reported to be between $1 \%$ and $7.9 \%$ among different South Korean populations (16-20). In United Republic of Tanzania, Houpt et al. reported a prevalence of $17.3 \%$ amongst HIV patients (21). In Guinea-Bissau, Cryptosporidium spp. had a prevalence of $7 \%$ and was the second commonest parasite with a marked seasonal variation and peak prevalence in the beginning of rainy seasons (22). The bovine-derived Cryptosporidium parvum accounts for many cases of human cryptosporidiosis in Iran (23). There are a lot of discrepancies between the studies in Iran, concerning the prevalence rate of Cryptosporidium spp. For example, Hamedi et al. reported a prevalence rate of $7 \%$ in children in southeastern Iran (24), but in our study, the prevalence of Cryptosporidium infection was $21.4 \%$ in children under 15 years of age.

Intestinal parasites are very common in developing countries. GIS technologies are often used for analysis of cryptosporidiosis in humans. Information collected through an diabetes $(24,25)$. After four days of familiarity with laboratory environment, the subjects were randomly divided into three groups: healthy control, diabetic and diabetic + aerobic

exceedingly spatial context can include management of epidemic events (Cryptosporidium infection in animals, humans and association between human outbreaks and animal infection), epizootiological surveillance (determination of infected animal species, endemic areas, management program for verification of cryptosporidiosis and scientific investigations (determination of Cryptosporidium species in an examined area). Lastly, the reportable initial application of GIS in Mazandaran province is expected to facilitate cryptosporidiosis surveillance and monitoring of Cryptosporidium spp.

\section{CONCLUSION}

This study is the first to evaluate prevalence of Cryptosporidium species in the Mazandaran Province using GIS. Our finding showed that living in low-altitude areas, rural areas without access to standard water sources and hot weather can increase the risk of cryptosporidiosis in the province. Moreover, the geospatial analysis showed that the prevalence of Cryptosporidium spp. was significantly higher in children less than 10 years of age compared to other age groups. Our findings and the GIS-derived data could be used to facilitate cryptosporidiosis surveillance and monitoring of Cryptosporidium spp. distribution in the study area.

\section{ACKNOWLEDGMENTS}

This study was financially supported by the Toxoplasmosis Research Center, Mazandaran University of Medical Sciences, Iran.

\section{CONFLICT OF INTEREST}

The authors declare that there is no conflict of interest regarding publication of this article.

\section{REFERENCES}

1. Hlavsa MC, Roberts VA, Kahler AM, Hilborn ED, Wade TJ, Backer LC, et al. Recreational water-associated disease-United States, 2009-2010. MMWR Morb Mortal Wkly Rep. 2014; 63(1): 6-10. [Google Scholar]

2. O'Donoghue PJ. Cryptosporidium and cryptosporidiosis in man and animals. Int J Parasitol. 1995; 25: 139-195. [DOI:10.1016/0020-7519(94)E0059-V] [PubMed] [Google Scholar]

3. Sturdee AP, Chalmers RM, Bull SA. Detection of Cryptosporidium oocysts in wild mammals of mainland Britain. Vet Parasitol. 1999; 80: 273-280. [DOI:10.1016/S03044017(98)00226-X] [PubMed] [Google Scholar] 
4. Warren C, Guerrant R. Clinical Disease and Pathology. $2^{\text {nd }}$ ed. Boca Raton, FL: CDC Press. 2008; 235-54. [DOI:10.1201/9781420052275-8]

5. Horman A, Korpela H, Sutinen J, Wedel H, Hanninen ML. Metaanalysis in assessment of the prevalence and annual incidence of Giardia spp. and Cryptosporidium spp. infections in humans in the Nordic countries. Int $\mathbf{J}$ Parasitol. $2004 ; \quad 34: \quad 1337-46$. [DOI:10.1016/j.ijpara.2004.08.009] [PubMed] [Google Scholar]

6. Davies AP, Campbell B, Evans MR, Bone A. Asymptomatic carriage of protozoan parasites in children in day care centers in the United Kingdom. Pediatr Infect Dis J. 2009; 28:838-40. [DOI:10.1097/INF.0b013e31819d646d] [PubMed] [Google Scholar]

7. Hellard ME, Sinclair MI, Hogg GG, Fairley CK. Prevalence of enteric pathogens among community based asymptomatic individuals. J Gastroenterol Hepatol. 2000; 15: 290-3. [DOI:10.1046/j.1440-1746.2000.02089.x] [PubMed] [Google Scholar]

8. Pettoello-Mantovani M, Di Martino L, Dettori G, Vajro P, Scotti S, Ditullio MT, et al. Asymptomatic carriage of intestinal Cryptosporidium in immunocompetent and immunodeficient children: a prospective study. Pediatr Infect Dis J. 1995; 14(12): 1042-7. doi: 10.1097/00006454-199512000-00003. [DOI:10.1097/00006454-199512000-00003] [PubMed] [Google Scholar]

9. Hunter PR, Hughes S, Woodhouse S, Raj N, Syed Q, Chalmers RM, et al. Health sequelae of human cryptosporidiosis in immunocompetent patients. Clin Infect Dis. 2004; 39(4): 504-10. doi: 10.1086/422649. [DOI:10.1086/422649] [PubMed] [Google Scholar]

10. Fayer R, Morgan U, Upton SJ. Epidemiology of Cryptosporidium: transmission, detection and identification. Int J Parasitol. 2000; 30: 1305-1322. [DOI:10.1016/S0020-7519(00)00135-1] [PubMed] [Google Scholar]

11. Sevinc F, Irmak K, Sevinc M. The prevalence of Cryptosporidium parvum infection in the diarrhoiec and non- diarrheic calves. Revue Méd Vét. 2003; 154: $357-$ 361. [View at Publisher] [Google Scholar]

12. Rinaldi L, Musella V, Biggeri A, Cringoli G. New insights into the application of geographical information systems and remote sensing in veterinary parasitology. Geospatial Health. 2006; 1: 33-47. [DOI: 10.4081/gh.2006.279] [PubMed] [Google Scholar]

13. Casemore DP, Armstrong M, Sands RL. Laboratory diagnosis of cryptosporidiosis. J Clin Pathol. 1985; 38: 1337- 1341. [DOI:10.1136/jcp.38.12.1337] [PubMed] [Google Scholar]

14. Rinaldi L, Bigg eri A, Carbone S, Musella V, Catelan D, Veneziano V, Cringoli G. Canine faecal contamination and parasitic risk in the city of Naples (southern Italy), BMC. Veterinary Res. 2006; 2: 29. [DOI:10.1186/1746-6148-2-29] [PubMed] [Google Scholar]
15. Haghdoost AA, Kawagu chi L, Mirzazadeh A, Rashidi H, Sarafinejad A, Banisadi AR, et al. Using GIS in explaining spatial distribution of Brucellosis in an endemic district in Iran. Iranian Journal of Public Health. 2007; 36: 27-34. [View at Publisher] [Google Scholar]

16. Yu JR, Lee JK, Seo M, Kim SI, Sohn WM, Huh S, et al. Prevalence of cryptosporidiosis among the villagers and domestic animals in several rural areas of Korea. Korean J Parasitol. 2004; 42: 1-6. [DOI:10.3347/kip.2004.42.1.1] [PubMed] [Google Scholar]

17. Lee JK, Song HJ, Yu JR. Prevalence of diarrhea caused by Cryptosporidium parvum in non-HIV patients in Jeollanam-do, Korea. Korean J Parasitol. 2005; 43: 111-114. [DOI:10.3347/kjp.2005.43.3.111] [PubMed] [Google Scholar]

18. Chai JY, Lee SH, Guk SM, Lee SH. An epidemiological survey of ryptosporidium parvum infection in randomly selected inhabitants of Seoul and Jeollanam-do. Korean J Parasitol. 1996; 34: 113-119. [DOI:10.3347/kjp.1996.34.2.113] [PubMed] [Google Scholar]

19. Seo M, Huh S, Chai JY, Yu JR. An epidemiological survey on Cryptosporidium parvum infection of inhabitants in Chorwon-gun, Kangwon-do. Korean J Parasitol. 2001; 39: 201-203. [DOI:10.3347/kip.2001.39.2.201] [PubMed] [Google Scholar]

20. Park JH, Kim HJ, Guk SM, Shin EH, Kim JL, Rim $\mathrm{HJ}$, et al. A survey of cryptosporidiosis among 2,541 residents of 25 coastal islands in Jeollanam-Do (Province), Republic of Korea. Korean J Parasitol. 2006; 44: 367-72. [DOI:10.3347/kjp.2006.44.4.367] [PubMed] [Google Scholar]

21. Houpt E, Bushen OY, Sam NE, Kohli A, Asgharpour A, $\mathrm{Ng} \mathrm{CT}$, et al. Short report: asymptomatic Cryptosporidium hominis infection among human immunodeficiency virus-infected patients in Tanzania. Am J Trop Med Hyg. 2005; 73: 520-522. [DOI:10.4269/ajtmh.2005.73.520] [PubMed] [Google Scholar]

22. Perch M, Sodemann M, Jakobsen MS, ValentinerBranth P, Steinsland H, Fischer TK, et al. Seven years' experience with Cryptosporidium parvum in GuineaBissau, West Africa. Ann Trop Paediatr. 2001; 21: 313318. [DOI:10.1080/07430170120093490] [PubMed] [Google Scholar]

23. Meamar AR, Rezaian M, Rezaie S, Mohraz M, Mohebali M, Mohammad K, et al. SSU- rRNA Gene Analysis of Cryptosporidium spp. In HIV Positive and Negative Patients. Iranian J Publ Hlth. 2006; 35: 1-7. [View at Publisher] [Google Scholar]

24. Hamedi Y, Safa O, Haidari M. Cryptosporidium infection in diarrheic children in southeastern Iran. Pediatr Infect Dis J. 2005; 24: 86-88. [DOI:10.1097/01.inf.0000148932.68982.ec] [PubMed] [Google Scholar]

\section{How to Cite:}

Soosaraei M, Daryani A, M Sharif, M Fakhar, Ziaei Hezarjaribi H. [Utilizing Geographic Information System in Evaluation of Spatial Distribution and Epidemiology of Cryptosporidium Species in Diarrheic Humans in Mazandaran Province, North of Iran ]. mljgoums. 2021; 15(1): 40-44. DOI: 10.29252/mlj.15.1.40 